\title{
A PERCEPÇÃO DOS ALUNOS DO PROGRAMA JOVEM APRENDIZ, REFERENTE AO USO DAS METODOLOGIAS ATIVAS EM SALA DE AULA
}

\author{
Mairiele Paula Carvalho Palma Santos*; Daniel Knebel Baggio; Maria Aparecida Duarte \\ Ciufa; Fabio da Silva \\ E-mail*: danibaggio@gmail.com
}

Faculdade Senac; Faculdade Senac, Unijui; Faculdade Senac, Blumenau; Faculdade Senac, Blumenau

DOI: $10.15628 /$ rbept.2020.9714

Artigo submetido em: mar/2020 e aceito em: abr/2020

\begin{abstract}
RESUMO
Este é um estudo sobre as metodologias ativas no processo de ensino e aprendizagem. $O$ objetivo é avaliar a percepção dos alunos referente ao tema. A relevância do trabalho está na necessidade de repensar o processo de ensino e aprendizagem. Utilizou-se a aplicação de questionário estruturado com perguntas fechadas direcionado aos alunos do programa Jovem Aprendiz do Seanc Blumenau, e contou com a participação de 333 alunos matriculados no ano de 2019. Os dados foram coletados a partir de técnica de levantamento com a aplicação de formulário, sendo os dados avaliados com o uso de técnicas quantitativas. Os resultados obtidos indicam preferência dos alunos em aulas com uso de recursos variados. Conclui-se que o aluno deve ser considerado na sua integralidade e parte ativa do processo, portanto as metodologias utilizadas devem promover a ação e reflexão, tornando o aprendiz sujeito com possibilidades de mudar a sociedade em que está inserido.
\end{abstract}

Palavras-chave: Metodologias ativas. Inovação na educação. Aprendizagem. Mindset.

\section{STUDENTS' PERCEPTION OF THE LEARNING PROGRAM CONCERNING THE USE OF ACTIVE CLASSROOM METHODOLOGIES}

\begin{abstract}
This is a study of the active methodologies in the teaching and learning process. The objective is to evaluate the students' perception regarding the theme. he relevance of the work is the need to rethink the teaching and learning process. A structured questionnaire with closed questions was applied to Senac Blumenau Young Apprentice students, and 333 students were enrolled in 2019. Data were collected using a form survey technique, and the data were evaluated using quantitative techniques. The results indicate preference of students in classes with use of varied resources. It is concluded that the student should be considered in its entirety and active part of the process, so the methodologies used should promote action and reflection, making the learner subject with possibilities to change the society in which it is inserted.
\end{abstract}

Key words: Active methodologies. Innovation in education. Learning. Mindset. 


\section{INTRODUÇÃO}

Muitas instituições de ensino neste país e em muitos locais do mundo não tiveram ao longo dos anos mudanças significativas no formato de como o conhecimento é construído com seus estudantes, mesmo com os estudos e avanços em novas metodologias de ensino que possam vir a substituir o formato atual de sala de aula. Assim, nas últimas décadas, o perfil do aluno vem se alterando e para se manter atualizado e ativo, o método ensino/aprendizagem também precisou mudar, principalmente, em um contexto socioeconômico que impõe expectativas de desempenho cada vez mais elevadas. (BARBOSA; MOURA, 2013).

Com as transformações pessoais e culturais que são vividas por todos atualmente em prazos cada vez menores, aliadas a facilidade e abrangência de novas formas de comunicação por meio de tecnologias cada vez mais acessíveis como a internet, há a necessidade de ser repensado o formato com que o conhecimento é construído dentro de uma instituição por meio dos professores, ou ainda repensar o próprio formato de uma sala de aula.

Araújo (2011), resume a situação atual na necessidade de reinventar a educação, tendo em vista que o modelo tradicional de ensino, consolidado no século XIX, "tem agora, também, de dar conta das demandas e necessidades de uma sociedade democrática, inclusiva, permeada pelas diferenças e pautada no conhecimento inter, multi e transdisciplinar, com a que vive-se neste início de século XXI". (ARAÚJO, 2011).

Desta forma, com a utilização das metodologias ativas, de forma antecipada, já durante a vida acadêmica o aprendizado é construído a partir de problemas e situações reais; os mesmos que os alunos vivenciarão depois na vida professional. (MORAN, 2015).

Esta pesquisa teve como público alvo jovens que frequentavam o Programa Senac de Aprendizagem. Este Programa propicia aos aprendizes competências voltadas à profissionalização e à cidadania, a partir da compreensão das características do mundo do trabalho e de seus fundamentos técnico-científicos. Este programa de qualificação prevê a realização de atividades teóricas e práticas dividindo o tempo do jovem entre o ensino regular, o curso de qualificação no Senac e a prática profissional na empresa. A organização do Senac e das empresas parceiras são definidas da seguinte forma: as aulas são ministradas duas vezes por semana no período matutino ou vespertino nas dependências do Senac e três vezes por semana o jovem vai para empresa podendo colocar em prática os conhecimentos adquiridos no curso.

Em âmbito nacional, o Serviço Nacional de Aprendizagem Comercial Senac, criado pelo Decreto-lei №. 8.621/46 em 10 de janeiro de 1946 (BRASIL, 1946), é uma Instituição de Ensino, de Direito Privado, sem fins lucrativos, administrada pela Confederação Nacional do Comércio e que oferece serviços de educação profissional em todo território nacional. 
O principal objetivo do Programa é promover a inclusão social e profissional, oferecendo formação técnico-profissional para o jovem, auxiliando-o para conseguir o primeiro emprego, haja visto, a dificuldade encontrada por essa população de pouca idade e sem experiência ao tentar se inserir no mundo do trabalho.

No momento da realização da pesquisa a Faculdade Senac de Blumenau/SC, estava com vinte turmas do Programa Senac de Aprendizagem Profissional Comercial em andamento, cada turma composta por uma média de 30 alunos, resultando no total 632 alunos.

Diante destes fatos e do cenário de estudo apresentado, este artigo propõe analisar a percepção dos alunos do Programa de Aprendizagem intitulado Jovem Aprendiz, sobre a utilização de metodologias ativas e mudanças do mindset, compreendendo quais são as estratégias de ensino que favorecem a aprendizagem desses adolescentes que hoje compõem a geração denominada "Z".

\section{REFERENCIAL TEÓRICO}

\subsection{ENSINO E APRENDIZAGEM}

A palavra ensino é utilizada cotidianamente em todos os seguimentos e principalmente no educacional, remetendo a uma percepção de ação. No entanto, essa palavra requer uma atenção muito maior por parte dos envolvidos com a educação formal, ou seja, professores/educadores e gestores educacionais, pois $o$ ato de ensinar requer planejamento sério e intencional. As ações que permeiam este ato precisam ser cuidadosamente planejadas, prevendo todas as etapas da aprendizagem, que deverão tornar 0 ensino significativo e reflexivo, capaz de ser colocado em prática para resolução de problemas e transmitido a outras pessoas pelo próprio aprendiz.

Pode-se apresentar a aprendizagem em determinadas etapas, pois, professor promove a aprendizagem quando ele considera a realidade objetiva ou as circunstâncias que envolvem o seu aluno, resgatando conhecimentos prévios que podem ser ampliados ou desmistificados, levando em consideração experiências individuais e as regras sociais existentes, e assim a forma como seu aluno aprende, mobilizando os conteúdos ministrados para resolução de problemas, pois, "Um saber somente importa ser ensinado quando instiga o aluno a uma associação ao mundo que vive, a realidade com o qual convive, os saberes que já acumulou". (ANTUNES, 2012, p. 33).

\subsection{ORGANIZAÇÃO DO PROCESSO ENSINO APRENDIZAGEM}

A organização do processo ensino aprendizagem pode ser definida em três etapas. Planejamento, Aplicação e Avaliação. 
Planejar é uma ação indispensável para a prática pedagógica, ou seja, planejar é condição indispensável no exercício da docência. O planejamento requer um envolvimento profundo do professor que idealiza suas aulas com vistas ao que deseja realizar e consequentemente ensinar aos seus alunos. (MASETTO, 2001).

Pode-se afirmar que, "à medida que as ações docentes são planejadas, evita-se a improvisação, garante-se maior probabilidade de alcance dos objetivos, obtém-se maior segurança na direção do ensino e também maior economia de tempo e de energia". (GIL, 2011, p. 99).

Vale lembrar que aulas expositivas não são as grandes vilãs do processo de ensino aprendizagem. O grande problema reside em manter-se apenas nesse tipo de estratégia de ensino. É querer ensinar diferentes conteúdos, promover a aprendizagem de diferentes conhecimentos para pessoas completamente distintas utilizando sempre a mesma estratégia. (ABREU; MASETTO, 1990).

A avaliação conclui as etapas de ensino aprendizagem pois, quando é ensinada alguma coisa a alguém o esperado é que haja aprendizado. Para Küller e Rodrigues (2013), os benefícios da avaliação costumam ir além da simples melhoria dos processos e dos desempenhos, o que já não é pouco. $O$ próprio processo de análise e comunicação franca sobre os erros e acertos proporciona experiências ricas de aprendizagens da competência e de relacionamento humano.

\subsection{METODOLOGIAS ATIVAS}

O processo de aprendizagem inicia desde o nascimento e não cessa enquanto há vida, aprendemos para garantir nossa existência, por isso sentimos a necessidade de transmitir os conhecimentos que adquirimos e que nos auxiliam a resolver problemas e perpetuar a espécie.

Para Freire aprendemos "[...] não apenas para nos adaptarmos à realidade, mas, sobretudo, para transformar, para nela intervir, recriando-a" (FREIRE, 1996, p. 28).

O processo de aprendizagem não é estático, requer movimento, precisa de atividade, portanto cada vez mais é necessário trazer situações práticas e vivências cotidianas para sala de aula. Por conta de toda a tecnologia disponível na sociedade, não podemos mais ficar presos em modelos de aulas tradicionais, é preciso possibilitar ao aluno a oportunidade de resolver problemas, mobilizando e articulando os conhecimentos aprendidos em sala de aula com a prática cotidiana.

Para Bacich e Moran (2018, p. 03), "[...] toda aprendizagem é ativa em algum grau, porque exige do aprendiz e do docente, formas diferentes de movimentação interna e externa, de motivação, seleção, interpretação, comparação, avaliação, aplicação". 
As metodologias utilizadas precisam ser dinâmicas e capazes de promover a interação entre professor/aluno, aluno/professor e aluno/aluno, haja vista, que o conhecimento se multiplica na troca.

Assim, as metodologias são grandes diretrizes que orientam os processos de ensino e aprendizagem e que se concretizam em estratégias, abordagens e técnicas concretas, especificas e diferenciadas. Metodologias ativas são estratégias de ensino centradas na participação efetiva dos estudantes na construção do processo de aprendizagem, de forma flexível, interligada e hibrida. (BACICH; MORAN, 2018).

Portanto, no conceito explicitado é possível definir que o aluno é o centro do processo de ensino aprendizagem e o professor atua como mediador dessa aprendizagem, agindo como facilitador do processo.

Neste processo dinâmico o aluno sente-se acolhido e valorizado, pois o professor torna-se capaz de proporcionar condições para que ele explore seu potencial construindo aprendizagens significativas, capaz de resolver situações problemas a partir das informações recebidas e transformadas em conhecimento.

Neste contexto o aluno é o protagonista da aprendizagem e o professor é articulador das etapas individuais e grupais deste processo, por ter capacidade para acompanhar, mediar, analisar, resultados, lacunas e necessidades a partir dos percursos realizados pelos alunos individualmente e em grupo.

Esse novo papel do professor é mais complexo do que o anterior de mero transmissor de informações. Requer dele uma preparação em competências muito mais amplas, além do conhecimento dos conteúdos. Ele precisa ter um olhar diferenciado para saber como adaptar-se ao grupo e a cada indivíduo que está em sua sala de aula. Precisando planejar, acompanhar e avaliar atividades significativas e diferentes. Vai requerer dele uma prática de ação-reflexão-ação muito mais intensa e suas atividades precisarão ser muito mais intencionais, tornando claro o objetivo a ser alcançado $(\mathrm{BACICH}$; MORAN, 2018).

\subsubsection{Aprendizagens ativas}

Para promover a aprendizagem é possível utilizar técnicas e recursos variados, considerando sempre o grupo que tal atividade é direcionada, qual a intenção da aprendizagem e o objetivo a ser alcançado. Também é preciso considerar a capacidade criativa de cada professor que será capaz de ampliar e muito as possibilidades aqui sugeridas. Pode-se elencar os seguintes tipos de aprendizagens ativas:

- Sala de Aula Invertida: Antes que o conteúdo seja abordado, os alunos buscam os conteúdos por meio de pesquisa para resolver um questionamento ou para promover um debate ou seminário, então o professor resgata os conteúdos estudados anteriormente a sala de aula 
e pode nivelar os conhecimentos de todos e até mesmo ampliar. Essa técnica vai requerer do aluno autonomia e responsabilidade, pois precisará cumprir os prazos conseguindo contribuir com a realização da técnica proposta. Ao mesmo tempo em que irá requerer do professor um aprofundamento maior no assunto, pois poderão surgir questionamentos mais amplos, como também poderão aparecer informações sem cunho científico.

Para Bacich e Moran (2018), depois que os estudantes desenvolvem o domínio básico de leitura e escrita nos primeiros anos do ensino fundamental, podemos inverter o processo: as informações básicas sobre um tema ou problema podem ser pesquisadas pelo aluno para iniciar-se no assunto, partindo dos conhecimentos prévios e ampliandoos com referências dadas pelo professor (curadoria) e com as que o aluno descobre nas inúmeras oportunidades informativas de que dispõe.

- Aprendizagem Baseada em Problemas: É um método de aprendizagem que desperta no aluno a curiosidade motivando-o a mobilizar seus conhecimentos para a resolução de um determinado problema. $O$ termo surgiu na década de 1960, PBL, do inglês problem-based lerning e no Brasil já é conhecido como ABP, aprendizagem baseada em problemas.

A aprendizagem baseada em problemas, de forma ampla, propõe uma matriz não disciplinar ou transdisciplinar, organizada por temas, competências e problemas diferentes, em níveis de complexidade crescentes, que os alunos deverão compreender e equacionar com atividades individuais e em grupo. (BACICH; MORAN; 2018, p.16).

O problema utilizado como recurso metodológico deve ter as seguintes características: a) O tema e o nível de complexidade de ser compatível com o conhecimento prévio do aluno; b) Apresentar dicas e sugestões para que o aluno identifique pontos de partida ou seja possibilidades de resolução a partir de sua pesquisa; c) Apresentar enunciado claro e objetivo, evitando que o aluno perca o foco desmotivando o estudo; d) Possibilite que o aluno mobilize e articule todos os seus conhecimentos.

- Aprendizagem Baseada em Projetos: Tem como objetivo promover a aprendizagem por meio de interação e partilha de conhecimento a partir de um desafio gerado no contexto do conteúdo apresentado. Dessa forma os alunos trabalham em grupo para a solução de um problema fazendo perguntas instigantes, investigando por meio de pesquisa para propor soluções e por vezes gerar inovação. Essa técnica de aprendizagem ativa permite uma avaliação formativa e também a valorização do produto resultante por meio de apresentação. (SENAC, DEPARTAMENTO NACIONAL, 2018, b).

Para Bacich e Moran (2018), por meio dos projetos, são trabalhadas também suas habilidades de pensamento crítico e criativo e a percepção de que existem várias maneiras de realizar uma tarefa, competências necessárias para o século XXI. Os alunos são avaliados de acordo com o desempenho durante as atividades e na entrega dos projetos. 
- Aprendizagem Baseada em Casos: Consiste em utilizar eventos reais ou que poderiam ser reais, envolvendo situações problemas mobilizando os alunos para que analisem o contexto e as circunstâncias de possíveis soluções. Os estudos de casos geralmente apresentam mais que uma solução possível. (SENAC, DEPARTAMENTO NACIONAL, 2018, b).

Os casos são constituídos ou selecionados a partir dos conhecimentos ou habilidades que precisam ser mobilizados, ampliados ou adquiridos. Os professores podem apresentar os casos de forma simples ou complexa e neles podem conter figuras, tabelas ou gráficos subsidiando a análise dos alunos.

- Aprendizagem Baseada em Jogos e "Gamificação": Nesta abordagem o professor utiliza-se de jogos lúdicos com finalidades educacionais. Estes jogos podem ser físicos ou digitais, também há a possibilidade de os alunos criarem seus próprios jogos, o que deve prevalecer é a intencionalidade para sua utilização e como em todos os jogos deve haver regras claras que os jogadores precisam cumprir. É importante que haja graus de dificuldades para serem vencidos, níveis que possam ser superados, gerando desafios. (SENAC, DEPARTAMENTO NACIONAL, 2018, b).

Dentre todos os jogos possíveis para adaptação educacional, os mais utilizados e que mais atendem a modalidade de ensino voltada para a qualificação profissional são os jogos empresariais. Estes jogos consistem em simular situações que ocorrem dentro das empresas, fazendo com que os jogadores assumam papéis previamente definidos e precisando tomar decisões.

O mercado apresenta uma infinidade de games para diversas idades e conteúdos pedagógicos. Para Simão (2017), o importante é criar um processo onde o professor pesquise games que vão de encontro aos seus objetivos pedagógicos. Alguns tipos se inserem de forma mais fácil para determinados conteúdos, como RPG, ótimo para ensino de idiomas, para temas transversais como sustentabilidade e empreendedorismo, e para temas da área de Humanas.

A partir da aplicação dos jogos o professor consegue observar o aprendizado dos alunos frente ao conteúdo, bem como perceber quais competências cognitivas e sócio emocionais foram desenvolvidas ou precisam ser mais bem trabalhadas.

$\mathrm{Na}$ visão de Sanches (2017), existe um problema capital, sempre ignorado, que é o da necessidade de promover o conhecimento capaz de apreender problemas globais e fundamentais para neles inserir os conhecimentos parciais e locais. É preciso ensinar os métodos que permitam estabelecer as relações mútuas e as influências recíprocas entre as partes e o todo em um mundo complexo.

$\mathrm{Na}$ aprendizagem baseada em jogos também são apresentados os jogos cooperativos, que visam promover entre os jogadores o espírito de equipe e a inclusão, pois nesta modalidade o que importa não é o rendimento 
individual e sim o sucesso coletivo, que é promovido pela interação de todos e as potencialidades individuais são valorizadas.

\subsection{MINDSET}

A capacidade humana de desenvolvimento cognitivo é sem dúvidas infinita e se faz necessária a compreensão de como o ser humano pensa, sente e age. O conhecimento existente no inconsciente desenvolvido através das diversas experiências ao logo do tempo pode gerar resultados na realidade humana baseados na escassez ou na abundância. Percebe-se que o resultado está associado ao condicionamento mental que o indivíduo desenvolve. (PONTES, 2018).

O Mindset ou atitude mental, define o modo como se encara a vida, a mentalidade, a construção do modelo mental que representa as ações e atitudes. Mentalidade é basicamente uma crença ou um sistema de crenças. Conforme filtra-se tudo através das crenças, cria-se a percepção e os pensamentos que moldarão as decisões, os sentimentos e comportamentos. (PONTES, 2018).

As crenças configuram a mente conforme moldam a percepção e a perspectiva. Entretanto, a maioria das crenças não produzem clareza de visão ou precisão de pensamentos, geralmente elas dificultam e impedem de se ver a realidade que de fato se apresenta. (GEORGE, 2017).

Conforme apontado por Dwerck (2017), o mindset não é simplesmente um traço de personalidade, mas sim, a relação que se estabelece com o trabalho, com outras pessoas, a forma como se educa os filhos e como se alcança sucesso, como percebe-se o mundo e como faz-se as escolhas que são norteadoras para superação e mudança.

Com o mindset fica mais claro para se perceber como as crenças pessoais impactam nas respostas que se dá frente aos desafios e oportunidades vislumbrados. O mindset mostra o modo otimista ou pessimista de enxergar diversas situações da vida e de como se portar diante delas. (PONTES, 2018).

Nessa perspectiva é importante entender a diferença entre os conceitos de mindset fixo e mindset de crescimento. A atividade mental fixa é aquela que faz com que os indivíduos acreditem que se não nascem com determinadas capacidades e dons, naturalmente, também não podem desenvolvê-los ao longo do tempo. Geralmente, as pessoas entendem que a inteligência que possuem é colocada em julgamento a todo momento e assim é gerada a insegurança em relação a isso. Essa tendência de não engajar impede que essa pessoa adquira novos conhecimentos que considera estarem em um nível de dificuldade maior do que ela pensa que é capaz. Tanto no âmbito profissional como no pessoal, quem tem a mentalidade mais fixa demonstra mais pensamentos negativos e tem a inclinação de ficar estagnado e desmotivado diante de situações complicadas que fogem do comum. (DWERCK, 2017). 
O segundo tipo de mentalidade é chamado de progressiva ou de crescimento. Ao contrário da mentalidade fixa, as pessoas com esse tipo de pensamento acreditam que seus talentos e habilidades podem ser desenvolvidos, desde que elas sejam pacientes, focadas, esforçadas e dedicadas. Um indivíduo com esse mindset tem a aptidão para transformar a dificuldade em uma oportunidade de aprender e evoluir. Se ele errar, não tem problema, pois acredita que é possível assimilar novos conhecimentos com o que não deu certo. $\mathrm{O}$ importante é enxergar os pontos positivos do processo e entender como corrigir os pontos negativos. Os profissionais com este perfil são aqueles que estão destinados ao sucesso, pois buscam vencer suas limitações e aprimorar seus conhecimentos diariamente. (DWERCK, 2017).

É importante ressaltar que uma pessoa não apresenta apenas um tipo de mindset em todos os aspectos de sua vida. Os mindsets variam conforme a situação, e em cada área da vida é comum ter a predominância de um tipo, nem sempre o mesmo. Não há uma classificação de um tipo de mindset como sendo o correto ou o errado, mas é possível perceber que o mindset de crescimento é aquele que possibilita mais êxito e que contribui de forma crucial para o desenvolvimento de um indivíduo. (DWERCK, 2017).

Segundo Dwerck (2017), para que haja transformação e aprimoramento pessoal e profissional, é preciso conhecer a própria mentalidade e mudá-la se necessário, pois o modo como se constrói o pensamento sobre as situações determina as ações e, consequentemente, determina a avaliação se as consequências destas atitudes serão interpretadas como negativas, neutras ou positivas.

\section{PROCEDIMENTOS METODOLÓGICOS}

Este trabalho se caracteriza como uma pesquisa descritiva $e$ exploratória. Segundo Hair Jr (2005), pesquisas descritivas em geral são estruturadas e especificamente criadas para medir as características descritas em uma questão de pesquisa. As hipóteses derivadas da teoria, normalmente servem para guiar o processo e fornecer uma lista do que precisa ser mensurado. Já pesquisas exploratórias têm como objetivo proporcionar maior familiaridade com determinado problema, com o intuito de torná-lo mais explícito ou a construir hipóteses. Seu planejamento tende a ser bastante flexível, pois interessa considerar os mais variados aspectos relativos ao assunto estudado. (GIL, 2010).

Para a obtenção dos dados, utilizou-se a técnica de levantamento ou survey no qual os dados foram obtidos por meio de aplicação um questionário estruturado com perguntas fechadas, sendo direcionado aos alunos que participam deste programa. Segundo Gray (2012), uma pesquisa de levantamento é uma descrição quantificada e detalhada de uma população, um mapa preciso ou uma mensuração precisa de um potencial. As pesquisas de levantamento envolvem a coleta sistemática de dados, seja por meio de entrevistas, questionários ou métodos de observação, de forma que a padronização tem importância central nas pesquisas de levantamento. 
A pesquisa contou com a participação de 333 alunos que responderam a um questionário online via plataforma do Google formulários, os quais foram enviados para os e-mails dos respectivos participantes. O período de envio contemplou os dias 25 a 29 de março de 2019.

O questionário foi elaborado pelos autores, contendo 21 questões relacionadas ao tema com questões contendo as opções de resposta "Sim" ou "Não. Utilizou-se também, escala Likert de 1 a 5, onde 1 representava "Não contribuem" e 5 "Contribuem muito" para algumas questões, e nas demais a escala de 1 a 5 , onde 1 representava "Totalmente insatisfeito" e 5 "Totalmente satisfeito".

Após a coleta dos dados a fase seguinte da pesquisa foi a análise dos dados colhidos junto aos participantes. Para Gil (2010) a análise tem como objetivo sumarizar e organizar os dados de tal forma que possibilitem o fornecimento de respostas ao problema proposto para a investigação. Ao analisar os dados obtidos pode-se perceber que se trata de uma pesquisa com dados quantitativos pois, Richardson (1999), afirma que a pesquisa quantitativa é realizada por meio de quantificação, tanto nas modalidades de coleta de informações quanto no tratamento das mesmas através de técnicas estatísticas.

\section{RESULTADOS E DISCUSSÕES}

O Programa Jovem Aprendiz é ofertado para adolescentes que se encontram na faixa etária de 14 a 24 anos incompletos. A geração ao qual este público está inserido é nominada de geração Z. É uma geração que já nasceu na era digital e não consegue conceber o mundo sem as tecnologias hoje existentes. São muito conectados e conseguem desenvolver várias atividades ao mesmo tempo.

A pesquisa contou com a participação de 333 alunos que responderam ao questionário aplicado por meio da ferramenta Google Forms e 94,6\% dos alunos que responderam à pesquisa correspondem a faixa etária entre 15 a 19 anos. Assim, este é um dado de grande relevância no que se refere a preparação, organização de conteúdos e planejamento das atividades a serem desenvolvidas para formação destes indivíduos. Também é importante salientar que $52 \%$ dos respondentes pertencem ao gênero feminino e $48 \%$ ao gênero masculino.

Outro dado que requer atenção refere-se ao grau de escolaridade deste grupo onde $5,4 \%$ possuem graduação incompleta, $8,1 \%$ ensino médio completo, 68,2\% apresentam ensino médio incompleto, $9 \%$ ensino fundamental completo e 9,3\% ensino fundamental incompleto, percebe-se a necessidade de um planejamento que privilegie a todos de forma a promover atividades desafiadoras e compatíveis a diversidade presente neste grupo no que se refere a idade, escolaridade e gênero.

Prosseguindo com a apresentação dos dados obtidos nesta pesquisa, a Figura 1 a seguir se refere sobre a opinião do aluno, identificando se ele 
aprende com mais facilidade em uma aula expositiva (tradicional) ou em uma aula com recursos variados onde haja trocas entre professor e aluno.

Figura 1: gráfico demonstrando o processo de aprendizagem em uma aula expositive versus aula com recursos variados

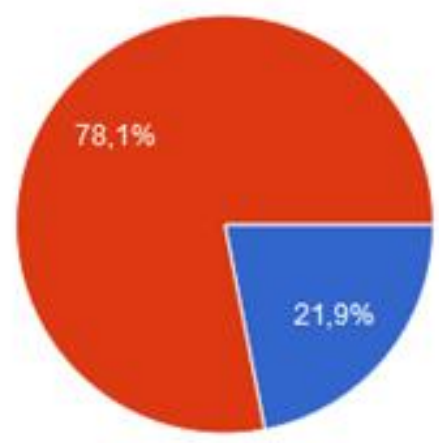

Aula expositiva (tradicional)

Aula com recursos variados

Fonte: desenvolvido pelos autores (2020)

Ao serem questionados sobre a forma como aprendem com mais facilidade, $78,1 \%$ dos alunos sinalizaram que aulas com recursos variados proporcionam uma maior facilidade para seu aprendizado, conforme gráfico 1 .

É interessante considerar que, conforme colocado por Suhr (2016), a premissa que reúne propostas diversas sob o título de metodologias ativas é preciso tirar o aluno da postura passiva frente ao conhecimento, que seria induzida pela forma expositiva tradicional ao colocar o professor como transmissor de verdades prontas e o aluno como receptor. Utilizando outras formas de organização do trabalho pedagógico, que levem à reflexão e ao desenvolvimento de níveis maiores de compreensão da realidade, o aluno compreende melhor o sentido dos referenciais teóricos estudados.

A figura 2 destaca a opinião dos alunos sobre a utilização de aulas somente expositivas, consideradas como tradicionais, no auxílio da aprendizagem. 
Figura 2: Gráfico sobre utilização de aulas somente expositivas no auxílio da aprendizagem

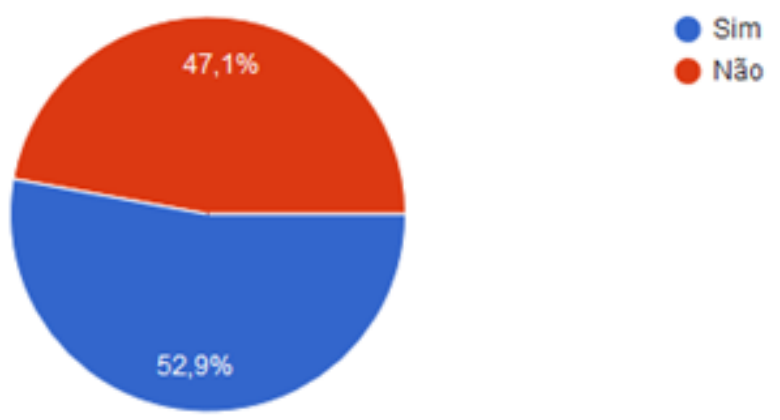

Fonte: desenvolvido pelos autores (2020)

A importância da identificação das preferências dos alunos está na sua utilidade direta para o planejamento e estabelecimento de estratégias e diretrizes didático-pedagógicas que possam mudar ou melhorar a percepção dos alunos sobre as condições de ensino, o que certamente levaria a um ganho de aprendizagem e ao aumento de interesse por parte dos mesmos. (CAMARGOS; CAMARGOS; MACHADO; 2006).

A opinião do aluno é fundamental para o ambiente de ensino e para aqueles que nele atuam como professores e gestores educacionais. Quando questionado aos alunos do Programa Jovem Aprendiz se as aulas somente expositivas auxiliam na aprendizagem, 52,9\% destes responderam que sim e $47,1 \%$ responderam que não. Nota-se com estes dados, que há uma proximidade com relação ao entendimento dos alunos sobre a utilização desta metodologia de ensino no auxílio da aprendizagem em contraponto a utilização das metodologias ativas, conforme Figura 2.

A aula expositiva, vista como tradicional, tem por base a transmissão do conhecimento do mestre para o aluno. Então, se bem planejada e realizada, essa estratégia de ensino em que o professor é o protagonista e conduz a turma por um raciocínio, pode ser também uma estratégia importante para ensinar determinados conteúdos e garantir a aprendizagem da turma. No entanto, este método não deve ser o único recurso usado em sala de aula, mas sim, fazer parte de uma sequência de atividades.

Madeira (2015), afirma que não há nada de errado com a aula expositiva, o importante é averiguar quando a estratégia de aprendizagem é a melhor para se alcançar determinados objetivos, e então, empregá-la com correção e preparo anterior adequado.

A Figura 3 expressa a avaliação dos alunos quanto à utilização de recursos variados para ensinar. 
Figura 3: grafico 3 sobre a avaliação dos alunos

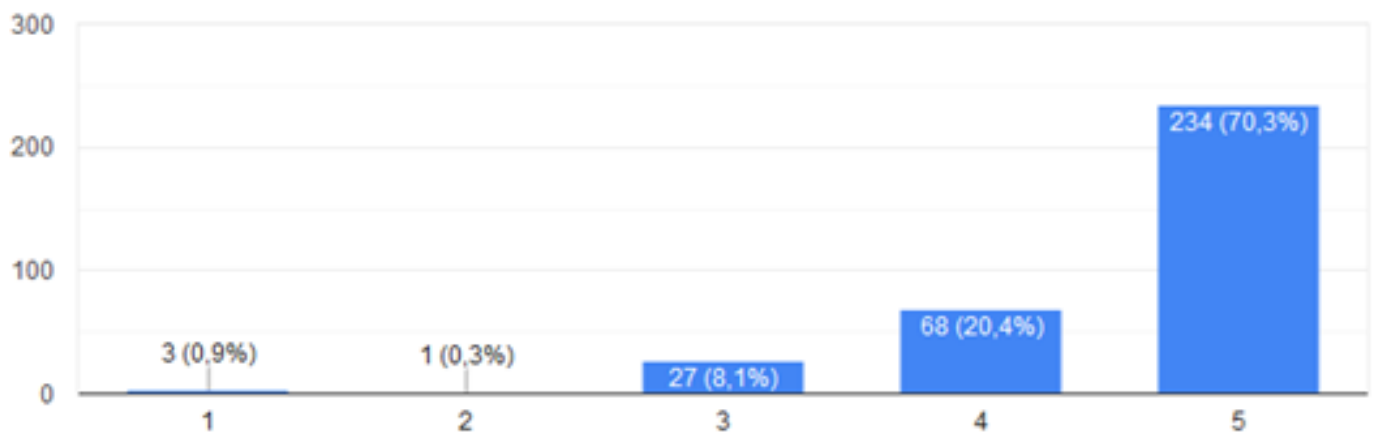

Fonte: desenvolvido pelos autores (2020)

A média de resposta foi de 4,59 , denota que os mesmos estão totalmente satisfeitos com os recursos variados utilizados para ministrar as aulas.

Para Bacich e Moran (2018), a aprendizagem mais profunda requer espaços de práticas frequentes (aprender fazendo) e de ambientes ricos em oportunidades. Por isso, é importante o estimulo multissensorial e a valorização de conhecimentos prévios dos estudantes para "ancorar" os novos conhecimentos. Aprendemos de muitas maneiras, com diversas técnicas e procedimentos, mais ou menos eficazes para conseguir os objetivos desejados. A aprendizagem ativa aumenta a nossa flexibilidade cognitiva, que é a capacidade de alternar e realizar diferentes tarefas, operações mentais ou objetivos e de adaptar-nos a situações inesperadas, superando modelos mentais rígidos e automatismos pouco eficientes.

Portanto, a utilização de recursos variados aplicados de forma correta são ferramentas que possibilitam a efetivação da aprendizagem auxiliando desta forma, a tornar a sala de aula um espaço propício para experimentação de novos conhecimentos e desenvolvimento de competências requeridas para a formação integral do indivíduo.

$\mathrm{Na}$ Figura 4 a seguir, é apresentado os dados obtidos referente a questão em que os alunos avaliam as atividades utilizadas em sala de aula pelos professores. 
Figura 4: gráfico sobre as atividades utilizadas em sala de aula pelos professors

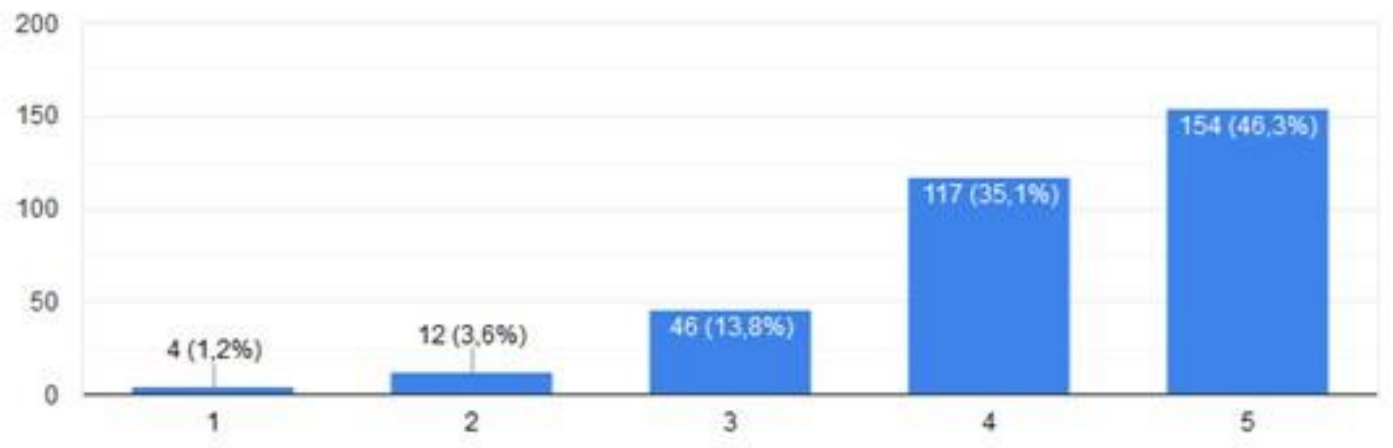

Fonte: desenvolvido pelos autores (2020)

Quando o professor oportuniza momentos desafiadores, mediando as situações de aprendizagem, desperta no aluno o sentimento de realização na busca pelo conhecimento e desenvolvimento pessoal e profissional. As atividades desenvolvidas devem despertar o interesse e gerar desafios positivos. Ao analisar o gráfico a cima, percebe-se que os alunos do Programa de Aprendizagem estão totalmente satisfeitos com as atividades utilizadas em sala de aula, apresentando a média geral de 4,22.

De acordo com Bacich e Moran (2018), a sala de aula pode ser um espaço privilegiado de cocriação, maker, de busca de soluções empreendedoras, em todos os níveis, onde estudantes e professores aprendem a partir de situações concretas, desafios, jogos, experiências, vivências, problemas, projetos, com os recursos que têm em mãos: materiais simples ou sofisticados, tecnologias básicas ou avançadas. O importante é estimular a criatividade de cada um, a percepção de que todos podem evoluir como pesquisadores, descobridores, realizadores; que conseguem assumir riscos, aprender com os colegas, descobrir seus potenciais. Assim, o aprender se torna uma aventura permanente, uma atitude constante, um progresso crescente.

Os alunos foram indagados se avaliavam as aulas administradas pelos professores do Programa Jovem Aprendiz como dinâmicas e interessantes. Para ministrar aulas dinâmicas e interessantes, os professores precisam planejar cuidadosamente as atividades que utilizaram, levando principalmente em conta os objetivos que pretendem alcançar. Para $92,2 \%{ }^{1}$ dos alunos do Programa Jovem Aprendiz que responderam à pesquisa, os professores administram aulas dinâmicas e interessantes.

$O$ ato de planejar requer organização e disciplina, nele deve ser previsto todas as situações que irão possibilitar que a aprendizagem aconteça.

\footnotetext{
${ }^{1}$ Resultado obtido com o questionário aplicado aos alunos. Pergunta de número 10. 
Tébar (2011) defende que o planejamento da atividade escolar para construção de determinados objetivos é a primeira exigência que todo mediador deve se propor, tanto com referência ao seu trabalho pessoal como ao modelo de planejamento que pretende projetar nos alunos. O educador deve ter consciência da importância do seu papel mediador para conseguir que os alunos assimilem e configurem seu próprio estilo de trabalho, que deve se manifestar em uma forma concreta de organizar e planejar todas as atividades que realizam, tanto escolares como pessoais. O planejamento é uma forma de preparar e adiantar-se a situações educacionais em todas as suas dimensões essenciais.

É preciso considerar também a relevância dos conteúdos ministrados em sala de aula, estes devem fazer sentido e ter significado, podendo ser utilizados no cotidiano por quem os aprende. Quanto mais próximos da realidade em que se vive estiverem, mais absorvido e compreendido serão. Os professores precisam estar atualizados e sincronizados com as mudanças e expectativas de seus alunos. Assim, de acordo com os dados coletados, $93,4 \%^{2}$ dos alunos que responderam à pesquisa consideram que os assuntos abordados pelos professores no Programa Jovem Aprendiz estavam atualizados.

Para Zabala (2010), formar em todas as capacidades do ser humano, com a finalidade de poder responder aos problemas que a vida apresenta, se converte, assim, na finalidade primordial da escola. A formação integral da pessoa como função básica, em lugar da função propedêutica. Um ensino que não esteja baseado na seleção dos "melhores", mas sim que cumpra uma função orientadora que facilite a cada um dos alunos o acesso aos meios que possam se desenvolver conforme suas possibilidades, em todas as etapas da vida; ou seja, uma escola que forme em todas as competências imprescindíveis para o desenvolvimento pessoal, interpessoal, social e profissional. Trata-se de uma educação também para o trabalho, mas sem perder a visão global da pessoa, como ser crítico diante das desigualdades e do comprometimento com a transformação social econômica em direção a uma sociedade na qual não apenas se garantisse o direito ao trabalho, como ainda este fosse desenvolvido em função ao desenvolvimento das pessoas e não apenas dos interesses de mercado.

Foi também investigado com os alunos, se os professores do Programa Jovem Aprendiz propiciavam espaços para a expressão das opiniões sobre os conteúdos abordados e assim oportunizassem a contribuição com a aprendizagem em sala de aula.

Oferecer ao aluno a oportunidade de protagonizar o seu aprendizado, implica também em democratizar o planejamento, pois se faz necessário entender como ele aprende. Para $95,5 \%{ }^{3}$ dos alunos que responderam à pesquisa, os professores oportunizam espaços que propiciam a expressar suas opiniões sobre os conteúdos abordados contribuindo com o processo de aprendizagem.

\footnotetext{
${ }^{2}$ Resultado obtido com o questionário aplicado aos alunos. Pergunta de número 11.

${ }^{3}$ Resultado obtido com o questionário aplicado aos alunos. Pergunta de número 12.

Vol. 2 (2020)
} 
De acordo com Küller e Rodrigues (2013), sempre que possível, especialmente considerando o tempo disponível, é interessante que o planejamento da ação seja efetuado com a participação dos alunos. Com isso, o professor estará proporcionando o desenvolvimento transversal de uma competência profissional básica: a de planejar o próprio trabalho. É importante salientar que o desenvolvimento da atividade de aprendizagem sempre é uma atribuição dos alunos, nunca do professor. A participação do professor, quando prevista, sempre será a de orientar, coordenar, acompanhar e apoiar a ação dos alunos.

$\mathrm{Na}$ pesquisa desenvolvida, quando questionados se eles se sentiam agentes participativos e responsáveis pela própria aprendizagem, $88,9 \%{ }^{4}$ dos alunos, responderam que sim, ou seja, de fato se sentiam participativos e responsáveis pela sua aprendizagem. Este sentimento é de extrema importância para formação social deste indivíduo que contribuirá de forma consciente para o desenvolvimento da comunidade em que está inserido, tornando-se capaz de propor e promover modificações no meio em que vive.

Para Bacich e Moran (2018), em todos os níveis há, ou pode haver, orientação ou supervisão, e ela é importantíssima para que o aluno avance mais profundamente na aprendizagem. Porém, na construção individual, a responsabilidade principal é de cada um, da sua iniciativa, do que é previsto pela escola e do que o aluno constrói nos demais espaços e tempos. O papel principal do especialista ou docente é o de orientador, ser tutor dos estudantes tanto individualmente como nas atividades em grupo, nas quais os alunos são sempre protagonistas.

Na Figura 5, é possível visualizar os resultados referentes ao interesse e motivação em participar das aulas do Programa Jovem Aprendiz.

Figura 5: Interesse e motivação do aluno em participar das aulas do Programa Jovem Aprendiz

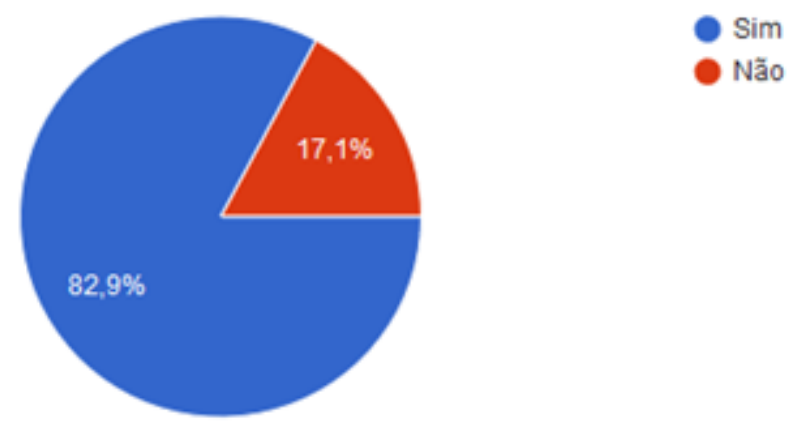

Fonte: desenvolvido pelos autores (2020)

${ }^{4}$ Resultado obtido com o questionário aplicado aos alunos. Pergunta de número 13. 
A motivação é um processo intrínseco que é construído pelo indivíduo e que pode ser gerado por meio de recursos e situações variadas. Para o processo de ensino aprendizagem este é um sentimento relevante, que deve ser considerado. Para $82,9 \%$ dos alunos, as aulas ministradas no Programa Jovem Aprendiz são interessantes e motivadoras. De acordo com Küller e Rodrigues (2013), motivar para a aprendizagem não significa necessariamente, como é comum às críticas menos fundamentadas à escola nova, tornar a situação de aprendizagem agradável para os alunos. Porém, é preciso torná-la necessária e estimulante; adiantar, garantir e mostrar a relevância do movimento ação-reflexão-ação proposto na situação de aprendizagem; evidenciar que aprendizagem decorrente é importante não apenas para um suposto uso em uma hipotética situação de vida futura; ressaltar a importância dessa aprendizagem para educação profissional em curso, para formação cidadã ou a vida de agora, no momento presente.

A Figura 6 a seguir, trata sobre a utilização que os alunos fazem das mídias sociais para aprimorar e ampliar os conteúdos trabalhados em sala de aula:

Figura 6: Utilização de mídias sociais para aprimoramento e ampliação dos conteúdos trabalhados em sala de aula

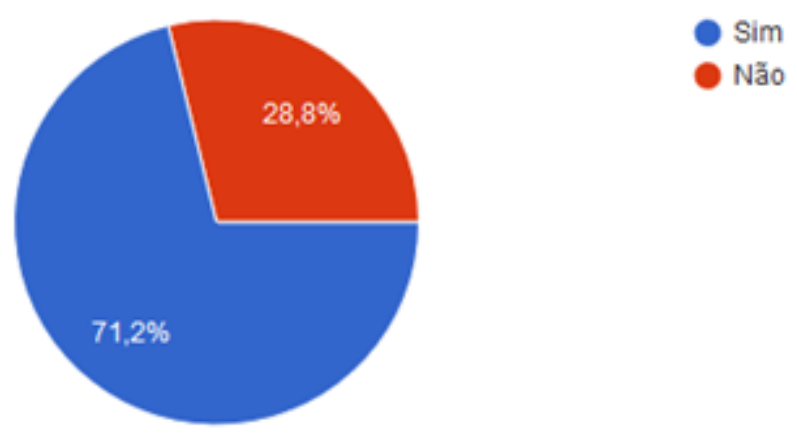

Fonte: desenvolvido pelos autores (2020)

Tecnologias da Informação e Comunicação têm sido consideradas um suporte importante para a educação porque abrangem diferentes formas de aprendizagem em oposição aos métodos tradicionais que privilegiam apenas um tipo de aprendizagem. (TREVELIN, PEREIRA, NETO; 2013).

Ensinar e aprender exigem atualmente muito mais flexibilidade espaçotemporal, pessoal e de grupo, menos conteúdos fixos e processos mais abertos de pesquisa e de comunicação. Para fins educacionais, as mídias e aplicativos têm se mostrado bastante úteis, pois algumas ferramentas se mostraram aplicáveis dentro da prática didática e metodológica diária, e também como extensão nas rotinas de trabalhos extras, aqueles em que o aluno leva as tarefas para casa e assim, aprimora e amplia o conhecimento sobre os conteúdos trabalhados em sala de aula. 
Nota-se com os dados coletados que a utilização das mídias sociais para auxílio educacional é realizada por $71,2 \%$ dos alunos do programa Jovem Aprendiz, conforme Figura 6.

A introdução do uso de mídias sociais e sua expansão na sala de aula, permite ao aluno um olhar diferenciado e ampliado no que se refere a melhor compreensão do conteúdo estudado em diversos vieses e significados. Sendo assim, cabe ao professor oferecer uma educação instigadora, estimulante, provocativa, dinâmica, ativa desde o começo e em todos os níveis de ensino, pois o professor que realiza essa aproximação no seu cotidiano coordena as trocas, enquanto os alunos relatam suas descobertas, socializam suas dúvidas e compartilham os resultados encontrados favorecendo assim a aprendizagem. (TREVELIN; PEREIRA; NETO, 2013).

Desta forma, com a utilização das mídias, o professor ratifica a importância da utilização das redes sociais na sua prática docente como oportunidade de melhorar a relação didática com os alunos, estimulando-os e motivando-os e assim, favorecendo o aprendizado de novas propostas pedagógicas que ensinam ao aluno sobre a importância de compartilhar outros saberes vindo de relações já estabelecidas em suas redes sociais e com a comunidade, mediante a realidade atual. Pois, de acordo, com Moran (2013), vive-se em um momento em que se pode aprender estando junto fisicamente e também conectados, pode-se aprender no mesmo tempo e ritmo ou em tempos, ritmos e formas diferentes.

Os alunos também foram questionados se acreditam que as redes sociais possam ser utilizadas como uma extensão da sala de aula ou facilitador no processo de aprendizagem e $90,1 \%{ }^{5}$ responderam positivamente, o que comprova que, com as tecnologias avançadas pode-se vivenciar processos participativos de compartilhamento do ensinar e aprender por meio da comunicação mais aberta, confiante, da motivação constante, de integração de todas as possibilidades da aula-pesquisa/aula-comunicação, em processo dinâmico e amplo de informação inovadora, reelaborada pessoalmente e em grupo, de integração do objeto de estudo em todas as dimensões pessoais: cognitivas, emocionais, sociais, éticas e utilizando todas as habilidades disponíveis do professor e do aluno. (LEITE, 2017).

A Figura 7 refere-se aos dados obtidos para a questão realizada se os alunos já tiveram a oportunidade de utilizar jogos em sala de aula para aprender algum conteúdo novo.

${ }^{5}$ Resultado obtido com o questionário aplicado aos alunos. Pergunta de número 18. 
Figura 7: utilização de jogos em sala de aula como auxílio na aprendizagem de um conteúdo novo

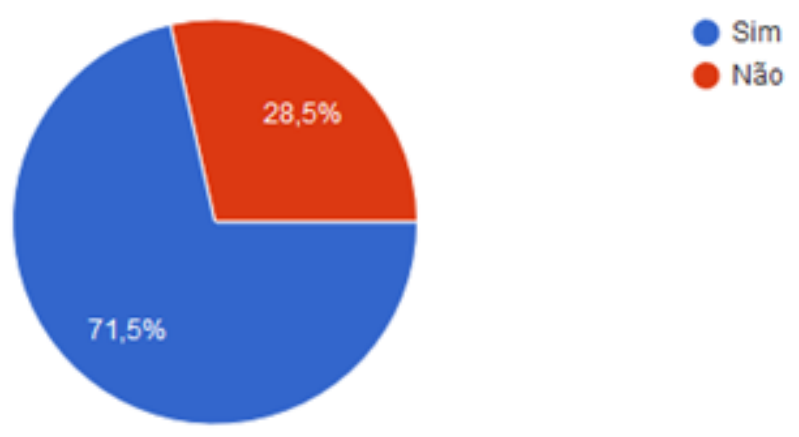

Fonte: desenvolvido pelo autor

Para Perrenoud (2000), a maioria das pessoas se interessam, em alguns momentos, pelo jogo da aprendizagem, se lhe oferecem situações abertas, estimulantes, interessantes. Há maneiras mais lúdicas do que outras de propor a mesma tarefa cognitiva. Não é necessário que o trabalho pareça uma "via crucis"; pode-se aprender rindo, brincando, tendo prazer.

Foi questionado aos alunos se já tiveram a oportunidade de utilizar jogos em sala aula para aprender algum conteúdo novo e apenas $71,5 \%$ responderam que sim, conforme Figura 7. Bacich e Moran (2018) defendem que, para gerações acostumadas a jogar, a linguagem de desafios, recompensas, de competição e cooperação é atraente e fácil de perceber. Jogos individuais ou para muitos jogadores, de competições, colaboração ou de estratégias, com etapas e habilidades bem definidas, tornam-se cada vez mais presentes nas diversas áreas de conhecimento e níveis de ensino.

Diante à pergunta "Você acredita que a gamificação utilização de jogos ajudaria a melhorar sua aprendizagem?" $94,3 \%{ }^{6}$ dos alunos responderam positivamente, ou seja, eles avaliam que a gamificação utilização de jogos auxilia-os na melhoria da aprendizagem.

De acordo com Küller e Rodrigues (2013), é preciso que a estratégia de preparação para a ação considere, situe e integre a aprendizagem atual no itinerário formativo escolar dos alunos. Eles precisam entender a conexão que existe entre a aprendizagem atual e as anteriores. Além disso, em cursos de educação profissional, os alunos precisam visualizar e perceber o papel que exerce a competência que será desenvolvida pela situação de aprendizagem na composição do perfil profissional de conclusão do curso que estão frequentando, pois, quanto mais relacionada ao cotidiano e as vivências, mais significativas serão as aprendizagens. Os jogos fazem parte do universo desses alunos, dessa forma, a utilização deste recurso favorece a correlação

${ }^{6}$ Resultado obtido com o questionário aplicado aos alunos. Pergunta de número 20. 
entre a teoria e a prática na ação a ser desenvolvida ou na resolução do problema apresentado.

Quando questionados se as salas de aulas temáticas, salas ambientes e laboratórios favorecem a aprendizagem, 97,9\% dos alunos responderam que sim.

De acordo com Gomes (2013), as práticas de laboratório, que na maioria dos cursos ocorrem concomitantemente à teoria, despertam grande interesse e motivam os candidatos a conhecer adequadamente os subsídios técnicos que antecedem a prática especifica. Em especial, o ato educativo se relaciona à intencionalidade dos currículos escolares, à abordagem metodológica e ao espaço onde se efetiva. Por essa via de compreensão, é possível afirmar que no Modelo Pedagógico Senac - cuja organização curricular e proposta pedagógica centra-se no desenvolvimento de competências, o espaço físico dos ambientes de aprendizagem também seja importante para o sucesso escolar dos alunos. Tal hipótese, já referenciada na literatura educacional especializada, afirma que o espaço físico é uma variável de impacto na aprendizagem, que deve se integrar ao currículo e dar suporte às metodologias educacionais empregadas. Em outras palavras, a organização desses espaços deve ser capaz de favorecer o tipo de concepção pedagógica, curricular e metodológica que fundamenta o ato educativo (SENAC, 2018a).

\section{CONSIDERAÇÕES FINAIS}

A partir do desenvolvimento deste estudo, foi possível avaliar a percepção dos alunos que participam do Programa Jovem Aprendiz, frente ao processo de ensino e aprendizagem. Em várias áreas do conhecimento humano novos processos e modelos vem sendo desenvolvidos e aprimorados com o passar dos anos, e o mesmo ocorre dentro do modelo educacional que tem sido alterado e melhorado para uma visão mais global e humana, criando a necessidade do constante desenvolvimento das metodologias e técnicas utilizadas para apropriação e ampliação do conhecimento.

A promoção de um ensino de qualidade perpassa a utilização de metodologias diversificadas, há a necessidade de pensar neste aluno como ser pertencente ao processo, que deve ser ofertado de maneira a promover uma educação integral, saindo do comum e promovendo a equidade.

Com a aplicação desta pesquisa, foi dado voz aos alunos, que puderam refletir e também manifestar suas percepções referente ao processo de ensino e aprendizagem, recebendo o protagonismo que lhes é de direito. Ao atribuir este papel, percebeu-se que os alunos compreendem a melhor forma para chegar ao aprendizado, demonstrando consciência do processo e contribuindo com ele. Além disso, a complexidade e amplitude do tema abordado, juntamente com o desenvolvimento deste trabalho gerou a necessidade de

\footnotetext{
${ }^{7}$ Resultado obtido com o questionário aplicado aos alunos. Pergunta de número 21.
} 
entendimento de outros temas que podem ser pesquisados gerando futuros estudos como:

- Investigar o impacto na utilização das metodologias ativas para a redução da evasão escolar.

- A modificação comportamental a partir do ensino pautado no desenvolvimento de competências.

- A utilização de Metodologias Ativas para diminuir a indisciplina em sala de aula.

- O Planejamento como ferramenta indispensável na prática docente.

- O aluno e o professor, várias faces do ensinar e aprender.

Durante a pesquisa percebeu-se a importância do docente no processo de aprendizagem, levando a necessidade de investigar sobre esta prática e a percepção deste profissional sobre o tema, gerando assim um estudo futuro.

Por fim, conclui-se que os objetivos propostos pela pesquisa foram todos alcançados, oportunizando avaliar que os resultados indicam alinhamento com a literatura, principalmente quanto a percepção dos alunos do Programa de Aprendizagem sobre a utilização de metodologias ativas como também as dificuldades enfrentadas em sala de aula e os benefícios na utilização das metodologias ativas.

\section{REFERÊNCIAS}

ABREU, M. C.; MASETTO, M. T. O professor universitário em aula. 11. ed. São Paulo: MG Ed. Associados. 1990.

ANTUNES. C. Professores e professauros: reflexões sobre a aula e práticas pedagógicas diversas. 6. ed. Petrópolis. RJ: Vozes. 2012.

ARAÚJO, U. F. A quarta revolução educacional: a mudança de tempos, espaços e relações na escola a partir do uso de tecnologias e da inclusão social. In: ETD: Educação Temática Digital. Campinas. v. 12. 2011.

BACICH. L; MORAN. J. (org). Metodologias ativas para uma educação inovadora: uma abordagem teórico-prática. Porto Alegre. Penso. 2018.

BARBOSA, E. F.; MOURA, D. G. Metodologias ativas de aprendizagem na educação profissional e tecnológica. B. Tec. Senac. Rio de Janeiro. v. 13, n. 2, p. 48 -67, maio/agosto. 2013.

BRASIL. DECRETO № 8.621/1946. Serviço Nacional de Aprendizagem. 1946.

CAMARGOS, M. A.; CAMARGOS. M. C. S.; MACHADO. C. J. Análise das preferências de ensino de alunos de um curso superior de administração de minas gerais. Revista de Gestão USP. São Paulo. v. 13, n. 2, p. 1-14, abril/junho. 2006. Disponível em: 
www.journals.usp.br/rege/article/viewFile/36554/39275. Acesso em: 15 abr. 2019.

DWERCK, C.S. Mindset: a nova psicologia do sucesso. São Paulo. Objetiva. 2017.

FREIRE. P. Pedagogia da autonomia: saberes necessários à prática educativa. Rio de Janeiro/São Paulo. Paz e Terra. 1996.

GEORGE. M. Mindsets: altere suas percepções, crie novas perspectivas e mude seu modo de pensar. Petrópolis, Vozes. 2017.

GIL, A. C. Como elaborar projetos de pesquisa. 5. ed. São Paulo: Editora Atlas S.A, 2010.

GIL, A. C. Didática do ensino superior. São Paulo: Atlas, 2011.

GOMES, H. M. A ação docente na educação profissional. 2 ed. São Paulo: Editora Senac. 2013.

GRAY, D. E. Pesquisa no mundo real. 2. ed. Porto Alegre: Editora Penso. 2012.

HAIR JR. J. F et al. Fundamentos de métodos de pesquisa em administração. Porto Alegre: Editora Bookman, 2005.

KÜLLER, J. A.; RODRIGUES, N. F. Metodologia de desenvolvimento de competências. Rio de Janeiro: Senac Nacional. 2013.

LEITE. B. S. Gamificando as aulas de química: uma análise prospectiva das propostas de licenciandos em química. Novas Tecnologias na Educação CINTED-UFRGS. ํㅡ 2V. 15. dezembro, 2017. Disponível em:

https://seer.ufrgs.br/renote/article/view/79259/46153. Acesso em: 23 abr. 2019.

MADEIRA. M. C. Situações em que a aula expositiva ganha eficácia. In: Educere - XII Congresso Nacional de Educação. Araçatuba. PUCPR. 2015. Disponível em: http://educere.bruc.com.br/arquivo/pdf2015/21752_10083.pdf. Acesso em: 15 abr. 2019.

MASETTO, M. T. Atividades pedagógicas no cotidiano da sala de aula universitária: reflexões e sugestões práticas. In: CASTANHO, S.;

CASTANHO, M. E. (orgs.). Temas e textos em metodologia do ensino superior. 7. ed. Campinas. SP: Papirus. 2001.

MORAN, J. M. A integração das tecnologias na educação. A Educação que desejamos: novos desafios e como chegar lá. 5 ed. Campinas: Papirus. 2013.

MORAN, J. M. Mudando a educação com metodologias ativas. Coleção Mídias Contemporâneas. Convergências Midiáticas, Educação e Cidadania: aproximações jovens. -PROEX/UEPG, Vol. II, 2015. Disponível em: http://uepffocafoto.wordpress.com//. Acesso em: 06 out. 2019.

PERRENOUD, P. Dez novas competências para ensinar. Porto Alegre: Artes Médicas, 2000. 
PONTES. E. H. S. Mindset - condicionamento mental para a melhor performance. Revista Psicologia e saberes. V 7. N 9. 2018. Disponível em: http://revistas.cesmac.edu.br/index.php/psicologia/article/view/858. Acesso em: 31/ jan. 2019.

RICHARDSON, R. J. Pesquisa social: métodos e técnicas. 3. ed. São Paulo: Atlas, 1999.

SANCHES, C. Inovação e tecnologia no ambiente escolar. Revista: INOVEDUC: Folha Dirigida. Outubro. pág.15. 2017. Disponível em: http://inoveduc.com.br/wp-content/uploads/2017/10/REVISTA-INOVEDUCOUTUBRO2017-SITE.pdf. Acesso em: 03 mar. 2019.

SENAC. Ambientes de aprendizagem. Senac. Departamento Nacional. 2018 a.

SENAC. Metodologias ativas de aprendizagem. Senac. Departamento Nacional. Rio de Janeiro. 2018 b.

SIMÃO, F. Ensino gamificado: o início de uma nova era. Revista: INOVEDUC: Folha Dirigida. Novembro. p. 67, 2017. Disponível em: http://inoveduc.com.br/wp-content/uploads/2017/03/REVISTA-INOVACAOEDUCACAO-NOVEMBRO-2016.pdf. Acesso em: 03 mar. 2019.

SUHR, I. R. F. Desafios no uso da sala de aula invertida no ensino superior. Revista. Transmutare. Curitiba, v. 1, n. 1, p. 4-21, jan./jun. 2016. Disponível em: https://revistas.utfpr.edu.br/rtr/article/view/3872. Acesso em: 28 abr. 2019.

TEBAR. L. O perfil do professor mediador: pedagogia da mediação. São Paulo. Editora Senac. 2011.

TREVELIN. A. T. C.; PEREIRA. M. A. A. NETO. J. D. O. A utilização da "sala de aula invertida" em cursos superiores de tecnologia: comparação entre o modelo tradicional e o modelo invertido. Revista de Estilos de Aprendizagem. № 12. Vol 11. outubro de 2013. Disponível em: http://learningstyles.uvu.edu/index.php/jls/article/viewFile/12/51. Acesso em: 17 abr. 2019.

ZABALA. A. Como aprender e ensinar competências. Porto Alegre. Artmed. 2010. 


\section{PESQUISA METODOLOGIAS ATIVAS SENAC BLUMENAU APLICADA AOS ALUNOS DO PROGRAMA JOVEM APRENDIZ.}

Pensando em melhorar os processos de aprendizagem e ensino para os Jovens Aprendizes, precisamos da sua colaboração respondendo a pesquisa abaixo que possibilitará a melhoria da atuação dos professores.

1) Idade:

( ) 10 a 14 anos

( ) 15 a 19 anos

( ) 20 a 24 anos

( ) 25 a 29 anos

( ) 30 a 34 anos

( ) 35 a 39 anos

( ) 40 a 44 anos

( ) 45 a 49 anos

( ) 50 a 54 anos

( ) 55 a 59 anos

( ) 60 anos ou mais

2) Sexo:

( ) Masculino ( ) Feminino

3) Escolaridade:

( ) Ensino Fundamental Incompleto

( ) Ensino Fundamental Completo

( ) Ensino Médio Incompleto

( ) Ensino Médio Completo

( ) Graduação Incompleto

4) Tipo de escola que cursa/cursou o ensino fundamental ou médio?

( ) Ensino Público ( ) Ensino Privado

5) Em sua opinião, você aprende com mais facilidade em uma aula expositiva (tradicional), ou em uma aula com recursos variados onde haja trocas entre professores e alunos?

( ) Aula expositiva (tradicional) ( ) Aula com recursos variados 
Em uma escala de 1 a 5, onde 1 representa "Não contribuem" e 5 "Contribuem muito", responda:

6) Você considera que as aulas administradas pelos professores do Programa Jovem Aprendiz contribuem para sua aprendizagem?

( ) 1( )2( ) 3( ) 4( ) 5

7) Você considera que as aulas administradas pelos professores do Programa Jovem Aprendiz contribuem para seu desenvolvimento pessoal e profissional?

( ) $1($ ) $2($ ) $3($ ) $4($ ) 5

Em uma escala de 1 a 5, onde 1 representa "Totalmente insatisfeito" e 5 "Totalmente satisfeito", responda:

8) Como você avalia as aulas administradas quando os professores utilizam recursos variados (Trabalhos em grupos, jogos, pesquisas, estudo de caso, resolução de problemas, projetos, fórum, ...) para ensinar?

( ) 1( )2( ) 3( ) 4( ) 5

9) Como você avalia as atividades utilizadas em sala de aula pelos professores?

( ) 1( )2( ) 3( ) 4( ) 5

Responda as questões abaixo selecionando entre as opções de "Sim" ou "Não":

10) Você avalia as aulas administradas pelos professores no Programa Jovem Aprendiz como dinâmicas e interessantes?

( ) $\operatorname{Sim}($ ) Não

11) Você considera que os assuntos abordados pelos professores no Programa Jovem Aprendiz são atualizados?

( ) $\operatorname{Sim}($ ) Não

12) Os professores do Programa Jovem Aprendiz propiciam espaços em que você possa expressar suas opiniões sobre os conteúdos abordados e assim possa contribuir com a aprendizagem em sala de aula?

( ) $\operatorname{Sim}($ ) Não

13) Você se sente agente participativo e responsável pela sua aprendizagem?

( ) $\operatorname{Sim}($ ) Não 
14) Você se sente interessado e motivado em participar das aulas do Programa Jovem Aprendiz?

( ) $\operatorname{Sim}($ ) Não

15) Na sua opinião as aulas somente expositivas (tradicionais) auxiliam na sua aprendizagem?

( ) $\operatorname{Sim}($ ) Não

16) Você considera que as atividades utilizadas em sala de aula pelos professores vão ao encontro aos seus objetivos?

( ) $\operatorname{Sim}($ ) Não

17) Você utiliza as mídias sociais para aprimorar e ou ampliar os conteúdos trabalhados em sala de aula?

( ) Sim ( ) Não

18) Você acredita que as redes sociais possam ser utilizadas como uma extensão da sala de aula ou facilitador no processo de aprendizagem?

( ) Sim ( ) Não

19) Você já teve a oportunidade de utilizar jogos em sala de aula para aprender algum conteúdo novo?

( ) Sim ( ) Não

20) Você acredita que a gamificação/utilização de jogos ajudaria a melhorar sua aprendizagem?

( ) Sim ( ) Não

21) Você acredita que salas de aulas temáticas, salas/ambientes e laboratórios favorecem a aprendizagem?

( ) Sim ( ) Não 